\title{
Canada and Aichi Biodiversity Target 11: understanding 'other effective area-based conservation measures' in the context of the broader target
}

\author{
D. MacKinnon ${ }^{1}$ - C. J. Lemieux ${ }^{2}$ K. Keazley ${ }^{3}$. \\ S. Woodley ${ }^{4} \cdot$ R. Helie ${ }^{5} \cdot$ J. Perron ${ }^{5} \cdot$ J. Elliott $^{6}$.

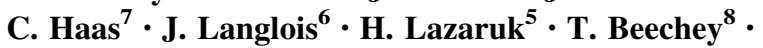 \\ P. Gray'
}

Received: 31 July 2015/Revised: 15 October 2015/Accepted: 23 October 2015/

Published online: 4 November 2015

(C) The Author(s) 2015

\begin{abstract}
A renewed global agenda to address biodiversity loss was sanctioned by adoption of the Strategic Plan for Biodiversity 2011-2020 and the 20 Aichi Biodiversity Targets in 2010 by Parties to the Convention on Biological Diversity. However, Aichi Biodiversity Target 11 contained a significant policy and reporting challenge, conceding that both protected areas (PAs) and 'other effective area-based conservation measures' (OEABCMs) could be used to meet national targets of protecting 17 and $10 \%$ of terrestrial and marine areas, respectively. We report on a consensus-based approach used to (1) operationalize OEABCMs in the Canadian context and (2) develop a decision-screening tool to assess sites for inclusion in Canada's Aichi Target 11 commitment. Participants in workshops determined that for OEABCMs to be effective, they must share a core set of traits with PAs, consistent with the intent of Target 11. (1) Criteria for inclusion of OEABCMs in the Target 11 commitment should be consistent with the overall intent of PAs, with the exception that they may be governed by regimes not previously recognized by reporting agencies. (2) These areas should have an expressed objective to conserve nature, be long-term, generate effective nature conservation outcomes, and have governance regimes that ensure effective management. A decision-screening tool was developed that can reduce the risk that areas with limited conservation value are included in national accounting. The findings are relevant to jurisdictions where the debate on what can count is distracting Parties to the Convention from reaching conservation goals.
\end{abstract}

Communicated by Karen E. Hodges.

C. J. Lemieux

clemieux@wlu.ca

D. MacKinnon

david.mackinnon2@novascotia.ca

K. Beazley

karen.beazley@dal.ca

S. Woodley

stephen.woodley@iucn.org

R. Helie

robertghelie@gmail.com 
Keywords Convention on Biological Diversity Aichi Biodiversity Target 11 .

Conservation - Protected areas · Other effective area-based conservation measures .

Effectiveness · Reporting

\title{
Introduction
}

People have recognized the importance of protected areas (PAs) for centuries, particularly as cornerstones of biodiversity conservation, now formally recognized in Article 8 of the 1992 United Nations (UN) Convention on Biological Diversity (CBD). More than 209,000 PAs encompass $15.4 \%$ of the planet's terrestrial and inland water areas and $3.4 \%$ of marine areas (Juffe-Bignoli et al. 2014). Since 1990, Canadian federal, provincial and territorial governments have doubled the number of PAs to more than 7000 terrestrial and 750 marine areas, which now represent 10.3 and $1 \%$ of Canada's terrestrial and marine area, respectively (Canadian Council on Ecological Areas 2014).

\author{
J. Perron \\ jpr.perron@gmail.com \\ J. Elliott \\ jessica.elliott@gov.yk.ca \\ C. Haas \\ claudia_haas@gov.nt.ca \\ J. Langlois \\ jean.langlois@gov.yk.ca \\ H. Lazaruk \\ heather.lazaruk@gov.ab.ca \\ T. Beechey \\ tombeechey@sympatico.ca \\ P. Gray \\ pgray250@gmail.com
}

1 Canadian Council on Ecological Areas \& Protected Areas Branch, Nova Scotia Environment, 1903 Barrington St., Suite 2085, PO Box 442, Halifax, NS B3J 2P8, Canada

2 Canadian Council on Ecolgical Areas \& Department of Geography \& Environmental Studies, Wilfrid Laurier University, Waterloo, ON N2L 3G1, Canada

3 Canadian Council on Ecological Areas \& School for Resource and Environmental Studies, Dalhousie University, Halifax, NS B3H 4J5, Canada

4 World Commission on Protected Areas, IUCN, 64 Chemin Juniper, Chelsea, QC J9B 1T3, Canada

5 Canadian Council on Ecological Areas, Ottawa, Canada

6 Canadian Council on Ecological Areas \& Yukon Parks, Department of Environment, Whitehorse, YT Y1A 2C6, Canada

7 Environment and Natural Resources, Government of the Northwest Territories, PO Box 1320, 600 5102 50th Ave., Yellowknife, NT X1A 2L9, Canada

8 Canadian Council on Ecolgical Areas \& Nature Matters, 91 Cooper St., Cambridge, ON N3C 2N5, Canada

9 BALCAMAN, Nanaimo, BC, Canada 
This increase in PAs denotes increased recognition by governments, aboriginal communities and private conservationists for the need to conserve valuable samples of ecosystems. However, despite the adoption of international agreements to conserve biodiversity, including the $\mathrm{CBD}$, and the expansion of global PA networks, biodiversity continues to decline around the globe (Millenium Ecosystem Assessment [MEA] 2005; Butchart et al. 2010). In response to this trend, in 2002, the Conference of the Parties to the CBD created the '2010 Biodiversity Target' "to achieve by 2010 a significant reduction of the current rate of biodiversity loss at the global, regional and national level as a contribution to poverty alleviation and to the benefit of all life on Earth". This target is endorsed by the World Summit on Sustainable Development, the UN General Assembly, and the Millennium Development Goals (MDG).

In 2010, Global Biodiversity Outlook 3 (GBO-3), the flagship publication of the CBD, concluded that countries failed to achieve the '2010 Biodiversity Target'. Most biodiversity indicators revealed that many direct pressures on biodiversity were constant or increasing (SCBD 2010a; Butchart et al. 2010). For example, the risk of extinction of many endangered species is increasing, and fragmentation and degradation of ecosystems continues. Similar trends are documented in Canada (Federal, Provincial and Territorial Governments of Canada 2010); its Fourth National Report to the CBD concluded that Canada had achieved "mixed" results in meeting the 2010 Biodiversity Target of "significantly reducing the rate of biodiversity loss" (Environment Canada 2009).

Given this failure to meet their targets, Parties to the CBD, including Canada, adopted a revised Strategic Plan for Biodiversity, including 20 'Aichi Biodiversity Targets' for the 2011-2020 period (decision X/2 in Nagoya, Japan, October) (SCBD 2010a). The 20 Aichi Biodiversity Targets are organized to help achieve the goals of the Strategic Plan. ${ }^{1}$ Given the need to account for unique national conditions, the Parties to the Convention agreed to set their own targets to meet strategic goals by 2012. Accordingly, the 20 Aichi Biodiversity Targets are considered more aspirational than binding. Canada's targets were released in 2015 (3 years overdue) and completely omit several Aichi Targets. ${ }^{2}$ Furthermore, there is concern in Canada and abroad about the wording of Aichi Target 11, which aims to track progress on the coverage and efficacy of the global PA network:

By 2020, at least 17 per cent of terrestrial and inland water, and 10 per cent of coastal and marine areas, especially areas of particular importance for biodiversity and ecosystem services, are conserved through effectively and equitably managed, ecologically representative and well connected systems of protected areas and other

\footnotetext{
1 The goals of the Strategic Plan for Biodiversity are to:

1. Address the underlying causes of biodiversity loss by mainstreaming biodiversity across government and society (Goal A);

2. Reduce the direct pressures on biodiversity and promote sustainable use (Goal B);

3. Improve the status of biodiversity by safeguarding ecosystems, species and genetic diversity (Goal C);

4. Enhance the benefits to all from biodiversity and ecosystem services (Goal D); and,

5. Enhance implementation through participatory planning, knowledge management and capacity building (Goal E).

${ }^{2}$ Most prominently, Strategic Goal A of the Strategic Plan for Biodiversity 2011-2020 (address the underlying causes of biodiversity loss by mainstreaming biodiversity across government and society) is entirely omitted from Canada's goals. Furthermore, there are no strategic links to five global targets, including Target 17 (commenced implementation of an effective, participatory and updated national biodiversity plan) and Target 20 (the mobilization of financial resources for effectively implementing the Strategic Plan for Biodiversity 2011-2020).
} 
effective area-based conservation measures, and integrated into the wider landscapes and seascapes. (Emphasis added) (SCBD 2010b).

Specifically, as Jonas et al. (2014) aptly point out, clear guidance is needed concerning the kinds of arrangements that constitute "other effective area-based conservation measures" (OEACBMs). Without this guidance, countries risk applying conservation policy that overlooks the diversity of ways of conserving and sustainable use of biodiversity, including by Indigenous peoples and local communities.

In Canada, the phrasing of Aichi Target 11 is of policy and reporting concern on several fronts. Some of Canada's privately-owned PAs and Indigenous Peoples' and Community Conserved Areas (e.g., Conservancies and Tribal Parks in British Columbia; see Turner and Bitonti 2011; Murray and King 2012; Stronghill et al. 2015) may qualify as OEACBMs in certain circumstances. However, it is unclear whether other area-based measures, such as fisheries closures and municipal water-supply protection areas, meet the intent of Aichi Target 11 (reformatted as Target 1 of the 2020 Biodiversity Goals and Targets for Canada). Well-governed and effectively managed PAs safeguard species and ecosystem services (Hutchings et al. 2012; Geldmann et al. 2013; Edgar et al. 2014; Halpern 2014; Watson et al. 2014; Juffe-Bignoli et al. 2014). In contrast, these other areas may have limited conservation benefit if they do not meet long-term conservation goals, including legal or other effective arrangements that prevent development threats within their boundaries. Further, the characteristics of areas that countries include as OEACBMs in national biodiversity reporting will significantly affect progress towards biodiversity conservation targets, and will have implications for the CBD's global PA and biodiversity conservation policy and reporting.

National and international commitments to establish PAs and OEABCMs for the protection of biodiversity, and to report on progress in meeting the targets, drive the requirement to derive information on PAs in a consistent and credible manner. Such reporting in Canada is a challenge given the complex nature of Canada's biodiversity conservation legacy, including how PAs are defined (e.g., Corson et al. 2014), the diversity in PA types (e.g. Gray et al. 2009), and governance arrangements implemented in the last several decades. The Canadian situation is similar to the global one, in which there is a "bewildering array" of areas with some sort of conservation objective (Dudley 2008). This has made it difficult to answer a seemingly simple question: "How much of Canada is covered by protected areas and other effective area-based conservation measures?".

In the absence of standardized, science-based reporting on Target 11 commitments, area-based measures of limited conservation value included in reporting mechanisms could cause false or misleading impressions of conservation progress. These areas will not necessarily result in real gains in biodiversity conservation as envisioned in the CBD's Strategic Plan for Biodiversity 2011-2020. While many conservation advocates promote PA expansion as a critical factor for conservation success (see Chape et al. 2005; Locke and Dearden 2005), the inclusion of areas with limited conservation effectiveness to advance political objectives will undermine the intent of the CBD's Strategic Plan for Biodiversity 2011-2020 and the Aichi process.

In light of this policy and reporting challenge facing Parties to the CBD, calls for standards to identify potential PAs have emerged (e.g., Lopoukhine and de Sousa Dias 2012; Woodley et al. 2012; Jonas et al. 2014). This paper thus reports on work to develop and rationalize guidance for reporting on PAs and OEACBMs in the Canadian biodiversity conservation context. Beyond the specifics of this case, the findings show promise for 
potential application in other countries within the context of the Convention and the IUCN (2012a). In support of this guidance work, three objectives were formulated:

(1) To develop an agreed cross-jurisdictional interpretation of 'protected areas' and 'other effective area-based conservation measures' in the context of Aichi Target 11 (and the CBD and Strategic Plan context from which it flows), and important commonalities and distinctions between them;

(2) To develop a standardized consensus-based approach and assessment tools for reporting on 'other effective area-based conservation measures'; and,

(3) To share the process, standardized assessment tools, and other outcomes of the facilitated dialogues at expert workshops in the Canadian biodiversity conservation context.

The findings described in this paper, while deliberated in a Canadian context, are relevant to jurisdictions where the debate on "what can we count?" distracts from the more important debate on "how will we reach our conservation goals?" In addition, the standardized approach can inform other conservation initiatives, including the United Nations Environment Program (UNEP) World Conservation Monitoring Centre (WCMC), which manages the World Database on Protected Areas (WDPA). ${ }^{3}$ The approach may also be useful to Aboriginal groups, environmental non-governmental organizations and private companies (e.g., forestry) in classifying special conservation areas.

To help practitioners, this paper provides advice on the kinds of PAs and OEABCMs appropriate in specific circumstances, and helps clarify issues that often spawn debate in their assessment. It serves as an example of collaboration designed to forward national and international biodiversity conservation targets. Finally, because the development of sciencebased advice on Aichi Target 11 is formative, it is important that strategies are disseminated quickly to advance thinking and practice. Accordingly, our objectives extend beyond a discussion of the outcomes of the expert workshops and describe other strategic issues (e.g., representation, connectivity, and management effectiveness) associated with Target 11.

\section{Methods}

\section{Case study area: Canada's protected areas: a brief overview of status, trends and governance}

In Canada, most federal, provincial and territorial agencies sponsor policy frameworks that guide PA management (e.g., management planning guides, policies, guiding principles, and programs) (Environment Canada 2015). Canadian jurisdictions have been influenced by international and national commitments related to PA coverage [e.g., the UN CBD (1992), Canadian Council of Ministers of Environment, Wildlife, and Parks (1992), and the Canadian Biodiversity Strategy (Environment Canada 1995)]. Canada was the first nation to ratify the UN CBD, responding by increasing the area protected and the diversity of ecosystems represented. (although there are significant differences in progress among Canadian jurisdictions).

As of 2014, PAs encompass approximately $10 \%$ of Canada's terrestrial area and $1 \%$ of marine area (Fig. 1) (Environment Canada 2015). The federal government employs three

\footnotetext{
${ }^{3}$ Data from the WDPA are, in turn, used by various UN bodies including the CBD to report on progress towards the targets of the Programme of Work on Protected Areas (PoWPA) and the Millennium Development Goal (MDG) indicators of protected area coverage. The data also form the basis of the biennial Protected Planet Report, which provides a summary update of all protected area data worldwide.
} 


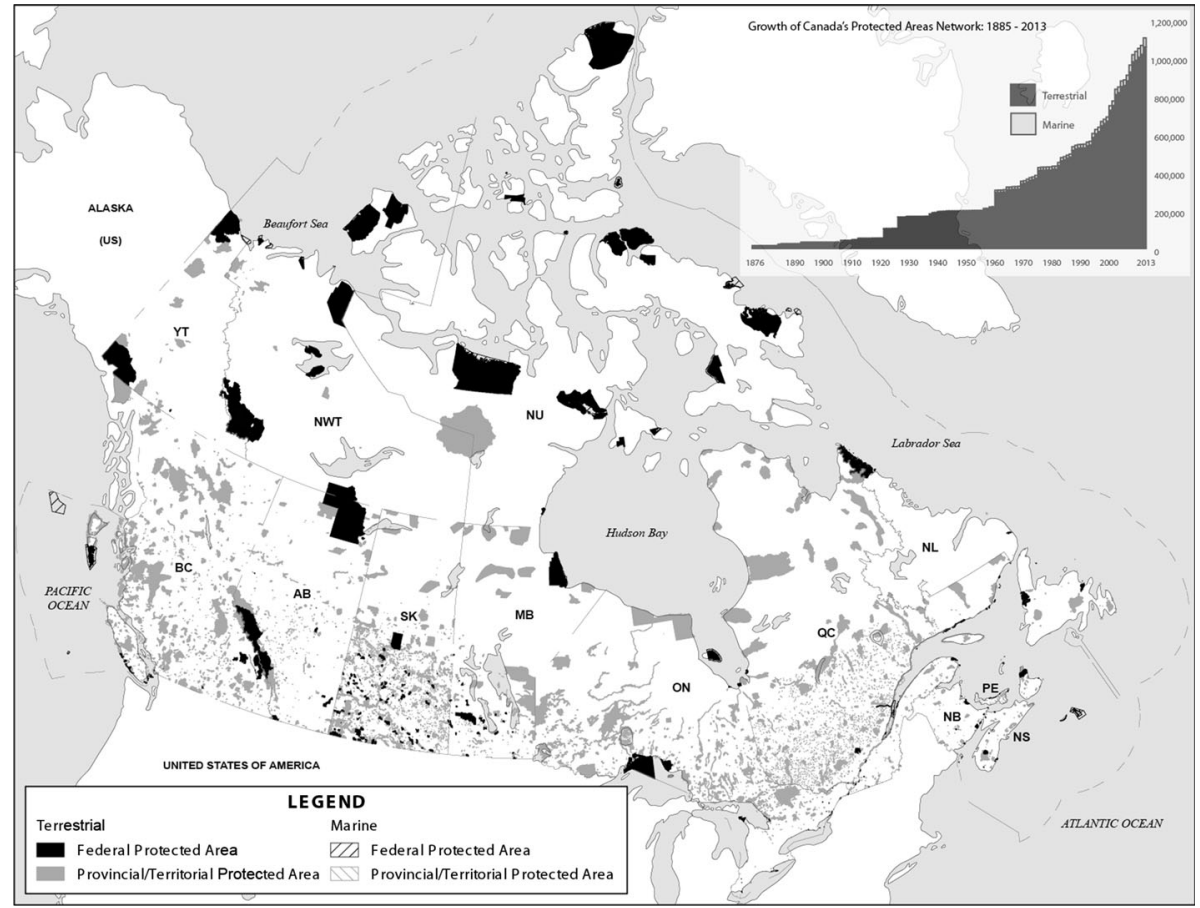

Fig. 1 Growth (ha) and extent of Canada's terrestrial and marine protected areas network [Source: Canadian Council on Ecological Areas, 2014: Conservation Areas and Reporting System (CARTS)]

agencies (Parks Canada Agency, Environment Canada, Aboriginal Affairs and Northern Development Canada) to administer $45 \%$ of the country's terrestrial protected areas. The provinces and territories administer most of the rest. Fisheries and Oceans Canada, Parks Canada and Environment Canada administer more than $90 \%$ of Canada's marine protected areas, and the provinces and territories administer most of the remaining (Environment Canada 2015). The accounting of privately protected areas, primarily through land trusts, in Canada is incomplete, but will account for less than $0.2 \%$ of the land base. Canada is $89 \%$ publically owned land (Neimanis 2007), and land trusts are focused in the southern $11 \%$ of Canada, most often in areas of high importance for biodiversity.

All 17 federal and provincial/territorial agencies responsible for terrestrial and/or marine PAs in Canada employ enabling legislation that provides for the establishment of PAs. Jurisdictions continue to focus on the enhancement of "representative area" networks, which is a primary objective of 11 of the 17 agencies. While the growth rate of Canada's marine PAs increased to $11.5 \%$ per year between 2006 and 2011, the growth rate of the terrestrial PA system slowed to $2.8 \%$ per year (in terms of total numbers) (Environment Canada 2015).

Most (91\%) of Canada's terrestrial PAs qualify as IUCN management categories Ia-II, which represent the highest levels of protection and naturalness (see Dudley 2008 for category descriptions). These categories provide rigorous protection of PA ecosystems (e.g., access control and prohibition of industrial activities and commercial resource extraction). Nearly $7 \%$ of Canada's terrestrial protected areas are classified as category IV 
or VI. These categories tend to emphasize protection of specific species, habitats, or ecosystems, often through management intervention (IV) or large, mostly natural areas that support a sustainable flow of ecosystem goods and/or services at a non-industrial scale. Only about $0.2 \%$ of Canada's terrestrial PAs are classified as category V. These represent the least natural, most transformed landscapes that still satisfy the IUCN definition of a PA (Dudley 2008, p. 24).

\section{The workshop process}

Workshops were led by the Canadian Council on Ecological Areas (CCEA), incorporated in 1982 as a national, non-profit organization with a mission "to facilitate and assist Canadians with the establishment and management of a comprehensive network of protected areas representative of Canada's terrestrial and aquatic ecological natural diversity". CCEA is composed of experts from all federal, provincial and territorial governments, as well as academic and NGO communities, and is a member of the International Union for the Conservation of Nature (IUCN). CCEA is responsible for the Canadian Conservation Areas Reporting and Tracking System (CARTS), which is used to track the status of Canada's PAs in a standardized manner. CARTS supports Canada's response to a variety of national and global initiatives, including the CBD, national 'state of the park' (SoP) reporting, and national reporting to the World Commission on Protected Areas (WCPA) (Canadian Council on Ecological Areas 2008).

To develop guidance for the community of practice on the scientific interpretation of OEABCMs, the CCEA convened three national workshops on Aichi Biodiversity Target 11 in February of 2013 (Ottawa, Ontario) and 2014 (Winnipeg, Manitoba), and March, 2015 (Edmonton, Alberta). Workshops foster the cross-fertilization of ideas by engaging a diverse group of stakeholders on complex policy issues (e.g., Halofsky et al. 2011; Moser and Ekstrom 2011; Lemieux et al. 2015). Participant recruitment for each workshop proceeded with the goal of achieving membership from each of Canada's 17 federal and provincial/territorial agencies responsible for terrestrial and/or marine PAs. Aboriginal organizations and NGOs responsible for land conservation and members of the broader scientific conservation community (e.g., academics, science-based NGOs) were also invited to participate in order to ensure an appropriate balance of perspectives. The workshops enabled participants to be involved directly in the Aichi Target 11 interpretation process, engaging their various perspectives (e.g., federal, provincial/territorial, private PA agencies, academics, NGOs) into a single cohesive forum (Schmoldt and Peterson 2000), unhindered by jurisdictional 'politics'.

The first of the four-day workshops (2013) focused on achieving consensus on the scientific interpretation of OEABCMs for reporting progress towards meeting Target 11. The second workshop (2014) developed a decision-screening tool for 'real world' scenarios in the Canadian context (e.g., screening private PAs, marine PAs, and other potential sites). The third workshop (2015) tested the decision-screening tool through in-plenary development and peer-review of case studies (report forthcoming). Workshops began with context-setting presentations by experts and panel discussions, and progressed to facilitated consensus-building and decision-support tool development. Initial phrasings of key issues pertaining to OEACBMs (e.g., scope of conservation objectives, governance regime, and effectiveness of measures) were drafted by a workshop coordinating team and interatively vetted by participants until consensus was achieved. Professional facilitators guided the discussions and notes were recorded. 
An iterative 'group stability' approach was adopted, with a threshold of $90 \%$ agreement as an indicator of consensus. Stability is defined as the consistency of responses between successive iterations (Dajani et al. 1979), and consensus, in this case, means general agreement or group solidarity in sentiment and belief (Mitchell 1991). To assess group stability, participants utilized three colored index cards: (1) green indicated agreement with the phrasing of a key issue; (2) yellow indicated agreement with the notion, with modification to phrasing; and, (3) red indicated rejection of the notion and phrasing. If requested modifications by a participant strongly deviated from the group response, the facilitator solicited the rationale. Facilitators also mitigated attempts to stigmatize or suppress participants' views that challenged group consensus. Sufficient clarification of the different viewpoints on key issues was a desirable goal of the approach. If any participant raised concern over phrasing through use of either a yellow or red card, iterations occurred until $90 \%$ agreement was achieved. The $90 \%$ threshold is considered stringent when compared to other consensus-based studies (e.g., Lemieux and Scott 2011; von der Gracht 2012). Further, while $90 \%$ was adopted as a guideline prior to the workshop, $100 \%$ consensus was achieved for most items.

\section{Results}

The workshops attracted jurisdictional representatives of Canadian PA and conservation agencies $(n=44)$, the international conservation community, including the Secretariat to the Convention on Biological Diversity (SCBD), the IUCN and the WCPA ( $n=3)$, science-based land stewardship organizations $(n=10)$, Aboriginal organizations $(n=1)$, and academia $(n=4)$ (Table 1$)$. Representatives from 15 of Canada's 17 federal and provincial/territorial agencies responsible for terrestrial and/or marine PAs participated in the workshops. ${ }^{4}$ Workshop participants created (1) consensus statements about the necessary characteristics of Target 11 OEABCMs, (2) a decision tool for screening protected areas and OEABCMs, and (3) recommendations for further development of the decisionscreening tool. The outcomes of each component are described below.

\section{Outcome 1: Conceptualizing Protected Areas, OEACBMs, and what should count towards reaching Aichi Target 11}

Early in the workshop, participants acknowledged that standardized categories of protected areas and OEABCMs would benefit cross-jurisdictional reporting. The IUCN and the CBD recognize that PAs can have a range of governance types, including private, Indigenous Peoples' and Community Conserved Areas, in addition to state-owned PAs. Upon analysis, many areas meet the IUCN standards for a PA and thus may fit an IUCN class and PA status in terms of governance. While the concept of PAs has existed for centuries, the term has been commonly used only since the 1970 s, in part to collectively describe the

\footnotetext{
4 Jurisdictional representatives are appointed to CCEA by their respective PA and conservation agencies, but participate by providing science-based input, rather than jurisdictional positions per se. Their participation does not necessarily imply agency support for CCEA workshop outcomes. The Government of Canada asknowledges CARTS as a primary data source for tracking Canada's Target 1 progress, but also that Canada is engaging in domestic and international conversations about how OEABCMs will be tracked (Federal, Provincial, and Territorial Working Group on Biodiversity, undated). Based on workshop outcomes and international guidance, CCEA intends to publish a guide for jurisdictional reporting of PAs and OEABCMs to CARTS.
} 
Table 1 Affiliations of workshop participants (workshops combined)

\begin{tabular}{|c|c|}
\hline Affiliation & Total \\
\hline \multicolumn{2}{|l|}{ Federal Government } \\
\hline Parks Canada Agency & 4 \\
\hline Environment Canada & 10 \\
\hline Fisheries and Oceans Canada & 6 \\
\hline Aboriginal Affairs and Northern Development Canada & 2 \\
\hline \multicolumn{2}{|l|}{ Provincial/Territorial Government } \\
\hline Alberta & 6 \\
\hline British Columbia & 2 \\
\hline Manitoba & 5 \\
\hline New Brunswick & 2 \\
\hline Newfoundland \& Labrador & 1 \\
\hline Northwest Territories & 2 \\
\hline Nova Scotia & 1 \\
\hline Ontario & 1 \\
\hline Quebec & 1 \\
\hline Saskatchewan & 1 \\
\hline Yukon & 1 \\
\hline \multicolumn{2}{|l|}{ Science-based, Non-Governmental Organizations } \\
\hline Canadian Parks and Wilderness Society (CPAWS) & 3 \\
\hline Nature Canada & 1 \\
\hline Nature Conservancy of Canada & 4 \\
\hline Nature Trust of New Brunswick & 1 \\
\hline Bird Studies Canada & 1 \\
\hline \multicolumn{2}{|l|}{ Aboriginal Organizations } \\
\hline Cree Regional Authority & 1 \\
\hline \multicolumn{2}{|l|}{ International Bodies } \\
\hline UN Convention on Biological Diversity Secretariat & 1 \\
\hline IUCN Global Program on Protected Areas & 1 \\
\hline World Commission on Protected Areas & 1 \\
\hline Academia & 4 \\
\hline Total: & 62 \\
\hline
\end{tabular}

"bewildering array" of types of areas dedicated to various nature conservation programs (Dudley 2008). In 2008 (updated 2013), IUCN published Guidelines for Applying Protected Area Management Categories, including a revised definition of PA: "a clearly defined geographical space, recognized, dedicated and managed, through legal or other effective means, to achieve the long-term conservation of nature with associated ecosystem services and cultural values" (Dudley 2008, p. 8). Debate ensued about the breadth of management regimes that "protected area" should encompass (see Corson et al. 2014 for example). Consequently, IUCN clarified its position on the distinction between PAs and other management regimes: "For IUCN, only those areas where the main objective is conserving nature can be considered protected areas; this can include many areas with 
other goals as well, at the same level, but in the case of conflict, nature conservation will be the priority" (Dudley 2008, p.10).

The term "other effective area-based conservation measures" was coined in the Strategic Plan for Biodiversity 2011-2020, specifically in the context of Aichi Target 11. This Strategic Plan was adopted by the Contracting Parties to the CBD at the tenth Conference of the Parties (COP10) in 2010 in Nagoya, Japan. Target 11 is clearly intended to help reverse the ongoing erosion of biodiversity by, among other things, stimulating an expansion of area dedicated to effective, in situ conservation of biodiversity, whether 'protected area' or otherwise. IUCN (2012b) has since recommended that, "national governments acknowledge the IUCN definition of a protected area, including the full range of protected area management categories and governance types, as a primary basis for the inclusion of protected areas to contribute towards meeting Target 11". Target 11 prescribes protected areas and OEABCMs characteristics (Table 2); however, it is clear that international guidance around OEABCMs in the context of Target 11 is lacking. CBD members have asked the IUCN to provide global guidance on the issue. Workshop participants agreed that additional guidance was needed.

Protected areas and OEABCMs are intended to share many of the same traits and address Strategic Goal C of the Aichi Biodiversity Targets (i.e., to "improve the status of biodiversity by safeguarding ecosystems, species and genetic diversity"). Thus, one might ask "How much can they actually differ?" In response, workshop participants provided consensus-based recommendations pertaining to PAs and OEACBMs, designed to assist practitioners with interpreting the IUCN PA categories (Table 3). These consensus statements describe the primary characteristics that qualify a spatial conservation measure as an OEABCM contributing to the objectives of Target 11 (i.e., purpose, long-term, importance of nature conservation objectives, nature conservation outcomes, and strength of measures). The statements can apply to all governance types recommended for recognition by Dudley (2008): (1) governance by government, (2) shared governance, (3) private governance, and (4) governance by indigenous peoples and local communities. Participants noted two kinds that have particular potential for increased recognition in Canada-certain Indigenous Peoples' and Community Conserved Areas, and certain private lands dedicated to biodiversity conservation (e.g., sites owned and managed by lands trusts such as the Nature Conservancy of Canada).

Table 2 The multiple dimensions of Aichi Target 11

\begin{tabular}{ll}
\hline Quantitative Targets by 2020 & $17 \%$ terrestrial area \\
& $10 \%$ marine area \\
Means of Conservation & Protected areas \\
& Other effective area-based conservation measures \\
Prescriptive Elements & Areas of particular importance for biodiversity and ecosystem services \\
& Effectively managed \\
& Equitably managed \\
& Ecologically representative \\
& Well-connected systems \\
& Integrated into wider landscapes and seascapes \\
\hline
\end{tabular}


Table 3 Consensus statements on the five major issues concerning "other effective area-based conservation measures"

\begin{tabular}{ll}
\hline Management theme & Consensus statement \\
\hline $\begin{array}{c}\text { Purpose of area-based } \\
\text { measure/intention }\end{array}$ & $\begin{array}{c}\text { Areas included under Target } 11 \text { as OEABCMs must have an expressed } \\
\text { purpose to conserve nature (biodiversity). We understand that this } \\
\text { purpose might be achieved as a co-benefit of other management } \\
\text { purposes or activities } \\
\text { Areas included under Target 11 as OEABCMs must be managed for the } \\
\text { long-term to be effective. We accept a working definition of long-term } \\
\text { to mean there is an expectation that conservation will continue } \\
\text { indefinitely } \\
\text { In areas included under Target 11 as OEABCMs, in cases of conflict with } \\
\text { other objectives, nature conservation objectives shall not be } \\
\text { compromised } \\
\text { Areas included under Target 11 as OEABCMs should result in effective } \\
\text { and significant nature (biodiversity) conservation outcomes. When there } \\
\text { are existing measures/areas that are to be considered as OEABCMs, } \\
\text { evidence of conservation outcomes should be used as part of the } \\
\text { screening process } \\
\text { Areas included under Target 11 as OEABCMs should have a management } \\
\text { regime that, through one or more measures that are effective alone or in } \\
\text { combination, can reasonably be expected to be strong enough to ensure } \\
\text { effective conservation, and if there are gaps, these will be addressed } \\
\text { over time }\end{array}$ \\
Strength of conservation \\
measures
\end{tabular}

\section{Outcome 2: The decision-screening tool for assessing candidates sites}

The second major outcome was the development of a draft decision-screening tool (Fig. 2) to guide jurisdictions in Target 11 reporting decisions, be it OEABCMs or PAs. This process resulted in three major products:

(1) Criteria to determine potential conservation effectiveness (i.e., Geographical scope; Scope of conservation objectives; etc.);

(2) Categories within each criterion that characterize a spectrum from most (red) to least (green) effective for conserving biodiversity; and,

(3) Acceptable thresholds for each criterion used to define and identify (a) Target 11 area (green), (b) conservation measures not sufficiently effective to be Target 11 area (red), and (c) measures that require further explanation or rationale to understand whether or not they are sufficiently effective to be Target 11 area (yellow).

These products comprise the decision-screening tool for reporting progress towards Aichi Target 11. Further, they demonstrate fundamental support for achieving all dimensions of Target 11 through expanded conservation efforts, as opposed to simply counting as many kinds of existing conservation measures as possible. Workshop participants reached consensus on many aspects of what should count towards Aichi Target 11 based on conservation 'priority' and 'effectiveness' as primary screening principles. Not all aspects of Aichi Target 11 were found useful for screening PAs and OEABCMs. For example, representativeness, connectedness, or equitability of management do not necessarily determine whether an area is a PA or OEABCM, but can determine whether effective conservation outcomes are achieved. Tracking of all aspects of Target 11, including 


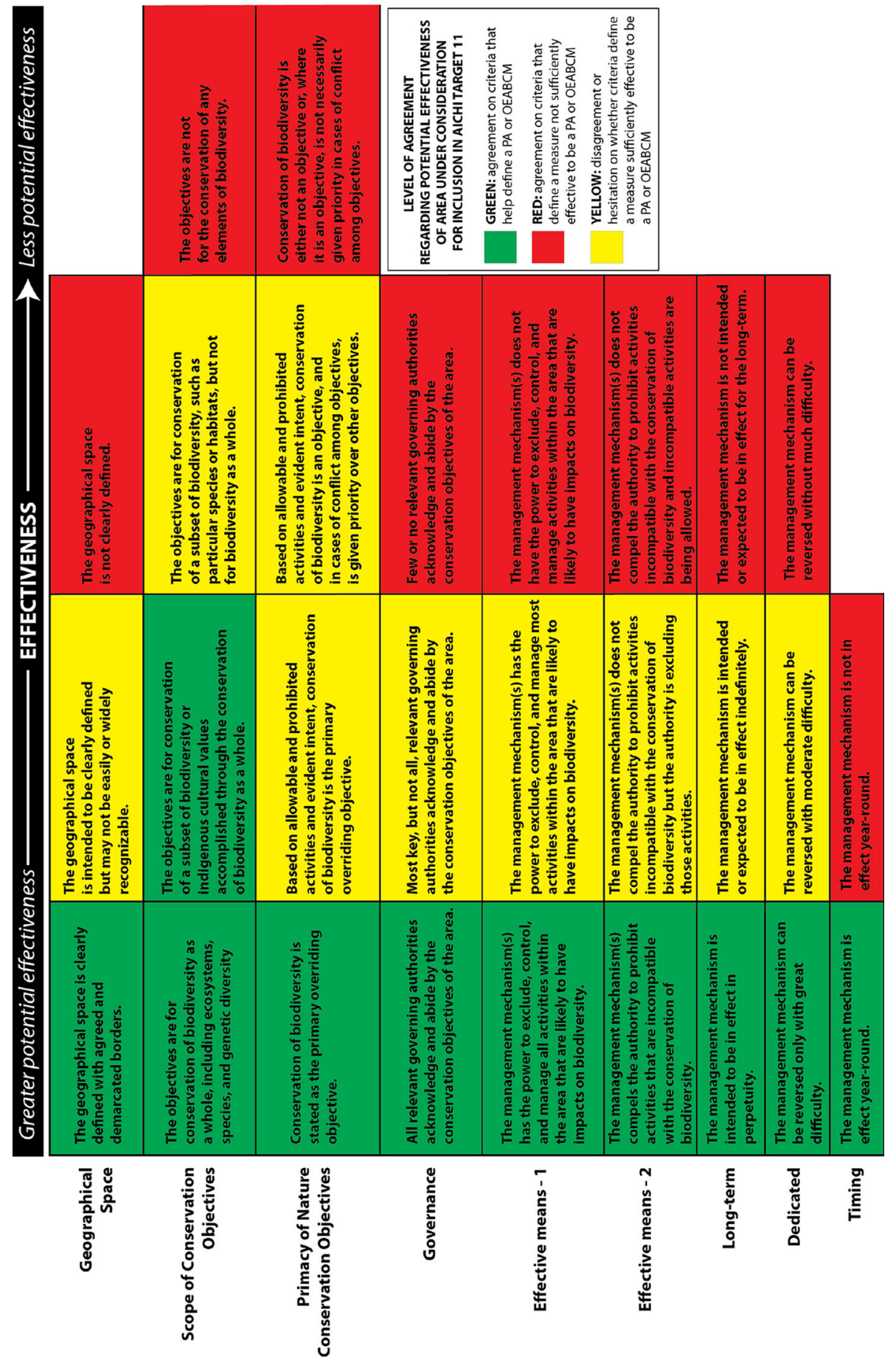


4 Fig. 2 Decision-screening tool for Aichi Target 11 candidate sites. The tool uses a green-yellow-red classification system. If the assessed conservation area satisfies all criteria (green in all respects), it is a Target 11 area; the jurisdiction decides whether to report it as a PA or as an OEABCM. If there is disagreement or uncertainty as to whether the measure is sufficiently effective to meet the criteria (yellow), then further explanation or rationale is required before the jurisdiction can decide whether or not to report it under Target 11. Essentially, all yellows should be converted to green or red through the following considerations: (a) if the conservation outcome is consistent with the intended effect of the "green" description, it should be converted to green; the jurisdiction then decides whether to report it as a PA or as an OEABCM; (b) if the conservation outcome is not consistent with the intended effect of the "green" description, but the organization demonstrates a commitment to addressing it within a reasonable timeframe, the area can be recognized as an 'Interim' or 'Projected' OEABCM; or, (c) if the conservation outcome is not consistent with the intended effect of the "green" description and the organization is not committed to addressing it within a reasonable timeframe, it should be converted to red; the jurisdiction does not report it as a PA or as an $\mathrm{OEABCM}$. If the area does not satisfy any single criterion or multiple criteria (red in any or all respect(s)), it is not a Target 11 area; the jurisdiction does not report it as a PA or as an OEABCM. (Color figure online)

equitability of management, was recognized as important by workshop participants and an area of future work for CCEA. The characteristics of areas to report as Aichi Target 11 areas defined through the above-described screening process include the following.

(1) The geographical space is clearly defined with agreed and demarcated borders. (It was noted that in rare instances (e.g. marine upwellings, ice edge areas) demarcation might derive from a feature that moves rather than a fixed location, however these can be agreed upon.)

(2) The objectives are for the conservation of:

a. biodiversity as a whole, including ecosystems, species, and genetic diversity; or,

b. a subset of biodiversity or indigenous cultural values accomplished through the conservation of biodiversity as a whole. In most cases, single-species management actions would not be considered under Target 11 but may fit other Aichi Targets.

(3) Conservation of biodiversity is explicitly stated as the primary objective. A range of objectives may exist for the site, but in cases of conflict, conservation should prevail.

(4) All relevant governing authorities acknowledge and abide by conservation objectives.

(5) The management mechanism has the power to exclude, control, and manage all activities within the area that are likely to have impacts on biodiversity.

(6) The management mechanism compels the prohibition of activities incompatible with biodiversity conservation.

(7) The mechanism is intended to endure in perpetuity.

(8) The mechanism can only be reversed with great difficulty.

(9) The mechanism is in effect year-round.

Decisions about whether or not conservation areas or measures should report as Aichi Target 11 areas derive from the screening tool (Fig. 2) through the following process.

(1) Compare the area (measure) against the descriptions in the screening tool.

(2) If the area corresponds in every respect (i.e., in every row of the table) with the descriptions in the green cells, it should be reported as an Aichi Target 11 area.

(3) If the area corresponds in at least one respect with a description in a red cell, it should not be reported as an Aichi Target 11 area.

(4) If the area corresponds in at least one respect to a description in a yellow cell, it exhibits one or more apparent gaps in effectiveness, suggesting that it may not achieve Aichi Target 11. 
(5) If all apparent gaps in effectiveness can be demonstrated as not real (i.e., if the conservation outcome is consistent with the intended effect of the "green" description), the area should be reported as an Aichi Target 11 area, with supporting rationale.

(6) If at least one of these apparent gaps in effectiveness is real (i.e., if the conservation outcome is not consistent with the intended effect of the "green" description), and the organization is not committed to addressing it within a reasonable timeframe, the area should not be reported as an Aichi Target 11 area.

(7) If the organization is committed to addressing all gaps within a reasonable timeframe, the area can potentially be reported as an 'interim' or 'projected' Aichi Target 11 area, but should be reported as an Aichi Target 11 area only once all gaps are addressed.

(8) The decision on whether an Aichi Target 11 area is a PA or an OEABCM is made by the jurisdiction in which the area occurs, based on comparison with the IUCN definition of a protected area.

\section{Outcome 3: Interpreting "sustainable use" within the context of protected areas and other effective area-based conservation measures}

Concepts of "sustainable" and "customary" use arise frequently in reference to PAs and OEABCMs and pertain to many human endeavors having little to do with biodiversity conservation. In recognition of this, workshop participants explored the boundaries on these useconcepts in the context of Target 11. The following statements of consensus were developed.

- Where sustainable or customary use is an objective for Aichi Target 11 areas (e.g., in category VI or V protected areas), it should be undertaken in a way that is integrated with and beneficial to biodiversity conservation and at a rate that does not produce significant impacts on biodiversity; and;

- Large-scale industrial uses are not appropriate in any Aichi Target 11 areas.

Similarly, efforts were made to develop a consensus statement on recommended minimum standards of effectiveness for Aichi Target 11 areas. The participants reached agreement on the following statements:

- Consistent with the objectives of the CBD, the Program of Work on Protected Areas, and the Strategic Plan for Biodiversity 2011-2020, all Aichi Target 11 areas should be managed to achieve the conservation of ecosystems and natural habitats and the maintenance and recovery of viable populations of species in their natural surroundings;

- We believe this requires, at a minimum, the prohibition of industrial or other uses that are likely to significantly impact biodiversity; and;

- Notwithstanding the foregoing, management activities such as those described in Principles and Guidelines for Ecological Restoration in Canada's Protected Natural Areas (Parks Canada Agency 2008) may be appropriate in Aichi Target 11 areas if undertaken for the purpose of biodiversity conservation (as determined through a science-based, peer-reviewed decision-making process).

Coming out of these workshops, the next steps for the CCEA will include illustrating the use of the Aichi Biodiversity Target 11 decision-screening tool with 'real world' examples, provided in an update of the Canadian Guidebook for the Application of IUCN Protected Area Categories (originally published in 2008). 


\section{Discussion}

The goal of the CBD Strategic Plan for Biodiversity is to increase the amount and effectiveness of areas for biodiversity conservation (SCBD 2010b). Target 11 aims to support this goal by accounting for PAs and OEABCMs. To measure progress, jurisdictions require the capacity to report on the number and area of effective PAs and OEABCMs. In Canada, reporting is conducted by self-reporting by federal, provincial and territorial jurisdictions through CARTS. A standardized framework would improve consistency in reporting across jurisdictions. CCEA provides science-based guidance to jurisdictions for reporting to CARTS; however, there are many examples of areas listed in the CARTS database that are not IUCN PAs and should not be reported (e.g., picnic parks). Adding new categories to CARTS (OEABCMs and interim OEABCMs), for which there is no prior reporting experience, may produce further inaccuracies. Consistent with interpretations by Woodley et al. (2012), Lopoukhine and de Sousa Dias (2012), and IUCN (2012), workshop participants acknowledged that the key differences between Target 11 OEABCMs and formally recognized PAs are the management mechanisms and lack of formal protected area declaration. Further, a key aspect of reporting areas under Target 11 is that they be 'effective' for biodiversity conservation. The principles and decisionscreening tool presented in this paper operationalize criteria for reporting PAs and OEABCMs under Target 11. If implemented, these should provide consistent means to assess and report across jurisdictions. The following sections discuss other important aspects of management effectiveness, representation, connectivity, and administration inherent in Target 11 and emerging from the workshop results.

\section{Management effectiveness}

There is an emerging body of literature focused on the conditions needed for PAs to meet a high quality of management effectiveness, particularly in the marine realm where better counterfactual data are available (e.g., Edgar et al. 2014; Halpern 2014; Watson et al. 2014; Juffe-Bignoli et al. 2014). The results of CCEA's workshops focus on criteria for reporting on PAs and OEABCMs under Aichi Biodiversity Target 11. This approach is not intended to diminish or discount other kinds of biodiversity conservation measures. All conservation measures are important components of a multi-faceted approach to slowing biodiversity declines. However, for the purpose of CBD reporting and cross-jurisdictional comparisons, workshop participants' agreed that a science-based, standardized approach is essential in both terrestrial and marine realms, and should use conservation effectiveness as the primary metric.

Workshop participants reached consensus on what should count towards Aichi Target 11, using conservation priority and effectiveness as primary screening principles (Fig. 3). Consistent with Article 8 of the CBD and Goal C of the Strategic Plan for Biodiversity 2011-2020 (SCBD 2010b), all Aichi Target 11 areas should be managed to achieve "the conservation of ecosystems and natural habitats and the maintenance and recovery of viable populations of species in their natural surroundings". However, capacity deficiencies affect the ability of many Canadian jurisdictions to effectively manage PAs. While many PA agencies in Canada incorporate ecological integrity objectives, very few have measures in place to manage for it (Environment Canada 2015). Therefore, the extent to which Canada's PAs are effective in conserving biodiversity is largely undocumented. Importantly, participants agreed that industrial or other uses that will likely impact 
Fig. 3 Conceptual representation of workshop results. The figure clearly illustrates that sites included in Aichi Target 11 reporting (PAs and OEACBMs) should have conservation objectives that are high priority (and clear) and high potential conservation effectiveness

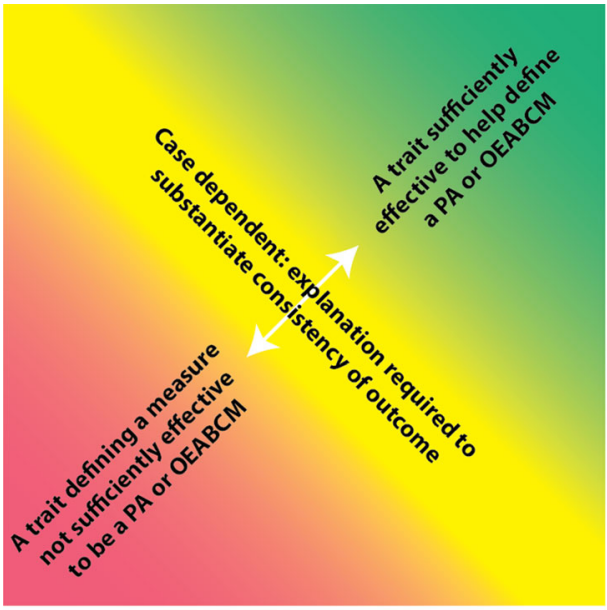

High priority and clear

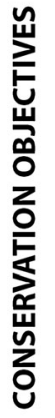

Low priority or unclear

\section{Low \\ EFFECTIVENESS \\ High (QUALITY OF PROTECTION)}

biodiversity are not appropriate in Aichi Target 11 areas. Where community-based sustainable or customary use is an objective (e.g., in category VI or V protected areas), it should proceed in a manner compatible with biodiversity conservation.

Globally, many marine PAs have been criticized for ineffective management, poor compliance, lack of expressed purpose to conserve biodiversity, siting according to political expediency alone (e.g., sited in areas with little resource development interest), and regimes that do not ensure conservation over the long-term (Edgar et al. 2014). In fact, recent research indicates that $59 \%$ of the world's marine parks are 'not ecologically distinguishable from fished sites' (Edgar et al. 2014). In Canada, only $0.11 \%$ of ocean area in marine PAs is fully closed to extractive uses (i.e., oil, gas, and fishing activities) (CPAWS 2015). From a conservation science perspective, the weak legal mechanisms in many marine PAs in Canada trigger the question of whether they meet the IUCN definition of PA, primarily because they remain open to industrial-scale harvest.

Questions about PA and OEACBM standards have significant political dimensions. Some governments and corporations have concerns about expansion of areas dedicated to biodiversity because they are seen as being economically unavailable for other uses. This concern drives political interest for recognition of areas with lower standards of protection (Locke and Dearden 2005). There is perceived political value for achieving Target 11 with the least economic costs, resulting in efforts to achieve the target by merely re-branding existing area-based conservation initiatives. Some governments may feel that the repercussions of failing to meet Aichi Target 11 commitments will exceed the cost of embracing lower standards to meet the target. Under an IUCN resolution (IUCN 2012a) Canada has committed to meeting Target 11 primarily through IUCN PAs. However, given the current rate of protected area establishment and the absence of a tangible national plan, Canada may have little progress to report under Target 11 in 2020. In addition, some Canadian PAs are threatened with being degazetted, which may result in jurisdictions reporting even less than currently. Despite these challenges, the question of how much has been effectively conserved is a technical question and should be separated from political dimensions. 
Reflection on the ever-expanding role of PAs highlights several emerging challenges with respect to management effectiveness. A total of 15 of 17 jurisdictions in Canada identify biodiversity conservation as the primary (9) or secondary (6) objective of protected areas as identified in legislation. However, PAs increasingly serve multiple roles, with an inherent risk to the primacy of biodiversity conservation. PAs are tasked with mitigating climate change, protecting ecosystem services, and providing sustenance, livelihoods (e.g., food security in MPAs), recreation and tourism (Watson et al. 2014). If PA mandates are excessively broadened, their effectiveness for biodiversity conservation may be undermined.

\section{Other strategic considerations: PA planning and management aspects}

Progress towards the development of representative networks of terrestrial and marine PAs in Canada gained substantial momentum in the early 1990s following Canada's ratification of the CBD. Ecological frameworks for representation were developed, and principles of protected area system design, including 'coarse-filter' representation and 'fine-filter' (e.g., rare or threatened species and ecosystems) approaches were applied. However, with the adoption of Target 11, the focus has shifted to reporting. Design and management aspects of Target 11 have been neglected. Issues of particular importance for biodiversity, effective and equitable management, representation, connection, and integration into wider landscapes and seascapes languish in the background. The 2020 Biodiversity Goals \& Targets for Canada Target 1 does not acknowledge these other aspects Target 11. Reports that focus solely on numerical targets, such as Canada's Fifth Report to the CBD (Environment Canada 2014) and GBO-4 (SCBD 2014), do not assess these other important elements, and therefore may give a misleading impression of Canada's progress. Indeed, Aichi Target 11 is about more than achieving quantitative targets. While percentage coverage components are receiving most attention, the target clearly states that reported areas should be of particular importance for biodiversity and ecosystem services, effectively and equitably managed, ecologically representative, well connected, and integrated into wider landscapes and seascapes. On all counts, achievements toward this Target may be more difficult than initially envisioned by some governments, and many are further away than the GBO-4 (SCBD 2014) suggests. Global trends indicate that Target 11 is not on track to be met by 2020, especially in the marine realm (see Tittensor et al. 2014 for example).

\section{Representation}

Aichi Target 11 includes achieving representation targets, but implementation has been difficult in Canada. While most of Canada's PA agencies continue to focus on protecting representative areas, with 11 of 17 agencies identifying this as a primary objective, more than half (9 of 17 agencies) also set objectives related to protecting a proportion of their land or ocean area (Environment Canada 2015). Area-based targets for representation are based on political targets, not derived from conservation science. Politically-based targets are generally much lower than conservation science would recommend (see Locke 2014), typically $\sim 12-17 \%$ versus $\sim 30-70 \% .^{5}$ Although some progress has been made on

\footnotetext{
5 Furthermore, this target has been largely agreed through a political process, with little public consultation on what areas should protect nature, and why. Indeed, recent results from the first-ever global survey on public perceptions of conservation needs revealed that people want significantly more protected natural space than currently exists. A poll of more than 7000 people from Australia, Brazil, China, India, South
} 
completing systems of protected areas representative of Canada's ecological regions, much work remains. Only one-third of jurisdictions (6 of 16) have claimed substantial representation of all of their terrestrial ecological regions (Environment Canada 2015).

Four of nine marine jurisdictions have have achieved 'partial' representation, and only as very small areas. The amount varies between 0 and $5.3 \%$, with 10 of 12 bioregions having $2.0 \%$ protection or less (Environment Canada 2015). More than half of protected area jurisdictions (9 of 16) now plan for the conservation of inland freshwater ecosystems within their protected areas networks, up from six in 2005 (Environment Canada 2015). However, freshwater and marine PA representation remains very poor. Overall, more work is required to better incorporate ecological representation into PA targets (Watson et al. 2015).

\section{Connectivity and integrated land-use planning}

Aichi Target 11 requires that PAs and OEACBMs be part of a connected system, integrated into wider landscapes and seascapes. Connectivity conservation seeks to address fragmentation through collaborative conservation (Worboys et al. 2010; Wyborn and Patrick Bixler 2013; Wyborn 2015). Connectivity is important to species, enhancing demographic and genetic flows that support persistence evolutionary potential (Lowe and Allendorf 2010). Lack of connectivity is a demographic threat to many migratory species (Carroll et al. 2015).

While most of Canada's PA jurisdictions (12 of 16) include policy objectives to protect large, intact or unfragmented areas, achievement has been difficult. Almost three quarters of the area protected is within a small number of protected areas (64) that are greater than $3000 \mathrm{~km}^{2}$, which is an estimated minimum size to avoid biodiversity loss (Environment Canada 2015).

Over half of Canada's PA jurisdictions recently identified a "lack of tools for connectivity between existing protected areas" as a serious constraint to planning (Environment Canada 2015). Jurisdictions also reported "incompatible use outside of protected areas" and "climate change" as serious threats to the ecological integrity of PAs (Environment Canada 2015).

Providing connectivity through a mosaic of PAs and other conservation areas will be crucial for immigration/emigration, the movement of genes (evolutionary flow), and unhindered flow of ecosystem functions, especially in a context of climate change (see Lemieux et al. 2011). In Canada, many private land protection programs (i.e., the Ontario Eastern Habitat Joint Venture, Nature Conservancy of Canada Nature Preserves, provincial/territorial tax incentive programs, conservation easements, and land trusts) contribute to greenway and blueway corridors that enhance connectivity and increase the resilience of ecosystems. The role of private organizations should be explored by jurisdictions committed to achieving Aichi Target 11 objectives and managing the impacts of climate change.

Footnote 5 continued

Africa, UK and USA shows people think that $50 \%$ of the planet's land and oceans should be protected, when in reality a mere $3 \%$ of the world's oceans and only $15 \%$ of land is currently under protection (London Zoological Society, 2014-Space for Nature). 


\section{Administrative effectiveness}

There is growing recognition in Canada that government austerity has significantly limited biodiversity conservation programs, including those related to PAs. According to the most recent assessment of PAs in Canada, almost two thirds of terrestrial agencies (10 of 16) report a lack information to plan PA systems to achieve biodiversity objectives (Environment Canada 2015). Similarly, marine PA agencies report that scientific information is lacking for the design of networks (Environment Canada 2015). Most agencies (14 of 16) claim that insufficient information exists to achieve conservation objectives related to ecological goods and services (Environment Canada 2015).

Cumulatively, government austerity at all levels has resulted in a shortage resources, hindering agencies in effectively implementing their biodiversity policies. Staffing has declined by $23 \%$ in Parks Canada Agency, and scientific staff has been reduced by more than one third (Office of the Auditor General of Canada 2013). Similar capacity limitations challenge provincial and territorial agencies. The Environmental Commissioner of Ontario and the British Columbia Auditor General observed that ministries responsible for PAs have failed to meet legislated responsibilities (Office of the Environmental Commissioner of Ontario 2013; British Columbia Office of the Auditor General 2010).

\section{Conclusions: halfway there, and 5 years to go}

Global decline of biodiversity is a serious environmental issue facing humanity, with the risk of drastic consequences to social-ecological systems as several thresholds and boundaries are breached and lead to rapid, large-scale and potentially irreversible changes (Steffen et al. 2015). There is no doubt that biodiversity conservation in the 21 st century will remain a significant challenge. In Canada, ecosystems continue to deteriorate and endangered species lists continue to grow (e.g., COSEWIC 2013). Furthermore, independent audits at multiple levels of government reveal a growing gap between biodiversity commitments and results (Office of the Auditor General of Canada 2013).

Pressure to establish PAs and report within multilateral environmental agreements may not only fail to deliver conservation benefits, but constrain the development of alernative approaches (Melick et al. 2012). As the global community moves towards adoption of Sustainable Development Goals in 2015, the story of Target 11 in the Canadian context offers lessons assessment of success towards targets-not least of which is that numerical indicators on their own are insufficient. Workshop participants from across Canada clearly stated that the notions conservation "primacy" and "effectiveness" were the most important, and that representation, connectivity, and integration into the wider landscapes and seascapes cannot be ignored in assessing candidate sites.

We have attempted to help the conservation community better assess their achievements in responding to Target 11 commitments. In light of the situations across Canada and globally where PAs are under pressure from industrial development, consideration of OEACBMs in national reporting warrants careful consideration. Sanctioning new designation(s) that are less effective than existing could establish precedence that hampers future efforts to create new PAs. It may even provide a wedge argument for those seeking to access valuable resources in existing PAs. Achieving targets must not simply be through rebranding of existing conservation areas as this will not result in the required conservation gains intended by the CBD. 
In Canada there is a need for a targeted expansion of the PA network (inclusive of achieving representation, biodiversity hotspot, and connectivity goals), followed by a commitment to improve effectiveness of PAs and rapid strengthening of stakeholder involvement, including Aboriginal peoples. Canada's Aboriginal peoples have contributed tens of thousands of square kilometres of PAs across the country, through modern land claims, treaties, or collaborative land-use plans. However, more must be done to reflect this reality in PA accounting systems, and to ensure that motives to secure resource rights amongst all stakeholders is in synergy with biodiversity conservation goals.

It is not clear how Canada will meet its biodiversity targets by 2020. Canada currently ranks 26th out of 34 OECD countries in percentage of lands set aside in terrestrial protected areas and 23rd in terms of marine waters, although 2 nd in terms of total extent of protected areas (Environment Canada 2015). Despite this, Canada has an unprecedented opportunity to protect natural values that are of national and global significance. It is one of the few remaining countries with large, unfragmented ecosystems, such in the Boreal forest and the Arctic, which still contain large-scale functioning natural processes and wideranging species. Many of these ecosystems are currently being considered for major landscape-changing industrial activities. The limited progress in Canada since the adoption of Target 11 is troubling, considering only 5 years remain until 2020. Without an updated national biodiversity plan and commitment of financial resources for implementation of its 2020 Biodiversity Goals and Targets for Canada, it appears highly unlikely that Canada will achieve its international commitment.

Acknowledgments The Canadian Council on Ecological Areas (CCEA) would like to thank the workshop participants who provided significant contributions to the outcomes reported on in this paper. We would also like to thank Jessica Cosham for editing assistance. Finally, thanks is extended to two anonymous reviewers for their suggestions and comments.

Disclaimer The content and views expressed in this paper are those of the authors and do not necessarily represent the opinions of their jurisdictions nor the agencies and organizations referred to in this paper.

Open Access This article is distributed under the terms of the Creative Commons Attribution 4.0 International License (http://creativecommons.org/licenses/by/4.0/), which permits unrestricted use, distribution, and reproduction in any medium, provided you give appropriate credit to the original author(s) and the source, provide a link to the Creative Commons license, and indicate if changes were made.

\section{References}

British Columbia Office of the Auditor General (2010) Conservation of ecological integrity in B.C. Parks and Protected Areas. Victoria. http://www.bcauditor.com/sites/default/files/publications/2010/report_ 3/report/OAGBC_Parks\%20Report_OUT2.pdf

Butchart SHM, Walpole M, Collen B, Van Strien A, Scharlemann JPW, Almond REA, Baillie JEM et al (2010) Global biodiversity: indicators of recent declines. Science 328(5982):1164-1168

Canadian Council of Ministers of Environment, Wildlife, and Parks (1992) A statement of commitment to complete Canada's networks of protected areas. Environment Canada, Ottawa

Canadian Council on Ecological Areas (CCEA) (2008) Canadian Guidebook: for the application of IUCN protected area categories 2008. CCEA occasional paper no. 18. Canadian Council on Ecological Areas, CCEA Secretariat, Ottawa, Ontario, Canada. http://ccea.org/cceawordpress/wp-content/uploads/2008/ 05/EN-IUCN-Guidebook-2008.pdf

Canadian Council on Ecological Areas (CCEA) (2014) Conservation areas reporting and tracking system (CARTS) v. 2013.12.31. Canadian council on ecological areas, Ottawa. http://ccea.org/en_carts.html 
Carroll C, Rohlf DJ, Li Y-W, Hartl B, Phillips MK, Noss RF (2015) Connectivity conservation and endangered species recovery: a study in the challenges of defining conservation reliant species. Conserv Lett 8(2):132-138

Chape S, Harrison J, Spalding M, Lysenko I (2005) Measuring the extent and effectiveness of protected areas as an indicator for meeting global biodiversity targets. Philos Trans R Soc B 360(1454):443-455

Convention on Biological Diversity (1992) 1992 Convention on Biological Diversity. 1760 UNTS 79, 31 ILM 818 [hereinafter the Biodiversity Convention]. http://cil.nus.edu.sg/1992/1992-convention-onbiological-diversity/

Corson C, Rebecca G, Rebecca W, Shannon H, Dan S, Shannon G, Maggie B et al (2014) Everyone's solution? Defining and redefining protected areas at the convention on biological diversity. Conserv Soc 12(2): 190

COSEWIC (2013) COSEWIC annual report 2012-2013. Committee on the status of endangered wildlife in Canada. http://publications.gc.ca/collections/collection_2013/ec/CW70-18-2013-eng.pdf

CPAWS (2015) Dare to be deep_-are Canada's marine protected areas really 'protected'? Annual report on Canada's progress in protecting our ocean. Canadian Parks and Wilderness Society, Ottawa. http:// cpaws.org/uploads/CPAWS_DareDeep2015_v10singleLR.pdf

Dajani JS, Sincoff MZ, Talley WK (1979) Stability and agreement criteria for the termination of Delphi studies. Technol Forecast Soc Change 13:83-90

Dudley N (ed) (2008) Guidelines for applying protected area management categories. IUCN, Gland. http:// data.iucn.org/dbtwwpd/edocs/PAPS-016.pdf

Edgar GJ, Stuart-Smith RD, Willis TJ, Kininmonth S, Baker SC, Banks S, Barrett NS, Becerro MA, Bernard ATF, Berkhout J, Buxton CD et al (2014) Global conservation outcomes depend on marine protected areas with five key features. Nature 506:216-220

Environment Canada (1995) Canadian Biodiversity Strategy: Canada's response to the Convention on Biological Diversity. Environment Canada, Hull. http://www.biodivcanada.ca/560ED58E-0A7A43D8-8754-C7DD12761EFA/CBS_e.pdf

Environment Canada (2009) Canada's fourth national report to the convention on biological diversity. BiodivCanada.ca. http://www.biodivcanada.ca/A53F6D68-2D76-4F2F-9056-D1C3D36D236C/Cana dasFourthNationalReportToTheUnitedNationsConventionOnBiologicalDiversity.pdf

Environment Canada (2014) canada's fifth national report to the convention on biological diversity. BiodivCanada.ca. http://biodivcanada.ca/default.asp?lang=En\&n=AE793BD2-1

Environment Canada (2015) Canadian protected areas status report 2006-2011. Environment Canada. http:// ec.gc.ca/ap-pa/default.asp?lang=En \&n=8EF4F871-1\&offset=1\&toc=show

Federal, Provincial and Territorial Governments of Canada (2010) Canadian Biodiversity: Ecosystem status and trends 2010. Canadian Councils of Resource Ministers, Ottawa. http://www.biodivcanada.ca/ A519F000-8427-4F8C-9521-8A95AE287753/EN_CanadianBiodiversity_FULL.pdf

Federal, Provincial, and Territorial Working Group on Biodiversity (undated): 2020 Biodiversity Goals and Targets for Canada-Goal C. By 2020, Canadians have adequate and relevant information about biodiversity and ecosystem services to support conservation planning and decision-making. BiodivCanada.ca. http://biodivcanada.ca/default.asp?lang=En\&n=9B5793F6-1\&offset=3\&toc=show

Geldmann J, Barnes M, Coad L, Craigie ID, Hockings M, Burgess ND (2013) Effectiveness of terrestrial protected areas in reducing habitat loss and population declines. Biol Conserv 161:230-238

Gray PA, Paleczny D, Beechey TJ, King B, Wester M, Davidson RJ, Janetos S, Feilders SB, Davis RG (2009) Ontario's natural heritage areas: their description and relationship to the IUCN protected area classification system. Queen's Printer for Ontario, Peterborough

Halofsky JE, Peterson DL, Furniss MJ, Joyce LA, Millar CI, Neilson RP (2011) Workshop approach for developing climate change adaptation strategies and actions for natural resource management agencies in the United States. J For 109(4):209-225

Halpern BS (2014) Conservation: making marine protected areas work. Nature 506(7487):167-168

Hutchings JA, Côté IM, Dodson JJ, Fleming IA, Jennings S, Mantua NJ, Peterman RM, Riddell BE, Weaver AJ, VanderZwaag DL (2012) Is Canada fulfilling its obligations to sustain marine biodiversity? A summary review, conclusions, and recommendations. Environ Rev 20:353-361

IUCN (2012a) Protected areas (Agenda Item 13.4) position paper. Eleventh meeting of the conference of the parties to the convention on biological diversity, Hyderabad, 8-19 Oct 2012. IUCN. http://cmsdata. iucn.org/downloads/iucn_cop11_position_paper_protected_areasfinal.pdf

IUCN (2012b) WCC2012Res035: Facilitating conservation through the establishment of protected areas as a basis for achieving Target 11 of the Strategic Plan for Biodiversity 2011-2020. IUCN. https://portals. iucn.org/library/sites/library/files/resrecfiles/WCC_2012_RES_35_EN.pdf

Jonas HD, Barbuto V, Jonas HC, Kothari A, Nelson F (2014) New steps of change: looking beyond protected areas to consider other effective area-based conservation measures. Parks 20(2):111-128 
Juffe-Bignoli D, Burgess ND, Bingham H, Belle EMS, de Lima MG, Deguignet M, Bertzky B, Milam AN, Martinez-Lopez J, Lewis E, Eassom A, Wicander S, Geldmann J, van Soesbergen A, Arnell AP, O'Connor B, Park S, Shi YN, Danks FS, MacSharry B, Kingston N (2014) Protected planet report 2014. UNEP-WCMC, Cambridge. http://www.unep-wcmc.org/system/dataset_file_fields/files/000/ 000/289/original/Protected_Planet_Report_2014_01122014_EN_web.pdf?1420549522

Lemieux CJ, Scott DJ (2011) Changing climate, challenging choices: identifying and evaluating climate change adaptation options for protected area management in Ontario, Canada. Environ Manag 48(4):675-690

Lemieux CJ, Beechey TJ, Gray PA (2011) Prospects for Canada's protected areas in an era of climate change. Land Use Policy 28(4):928-941

Lemieux CJ, Thompson JL, Slocombe DS, Schuster R (2015) Climate change collaboration among natural resource management agencies: lessons learned from two U.S. regions. J Environ Plan Manag 58(4):654-677

Locke H (2014) Nature needs half: a necessary and hopeful new agenda for protected areas in North America and around the World. George Wright Forum 31(3):359-371

Locke H, Dearden P (2005) Rethinking protected area categories and the new paradigm. Environ Conserv 32(1): $1-10$

Lopoukhine N, de Sousa Dias BF (2012) Editorial: what does Aichi Target 11 really mean? Parks 18:1

Lowe WH, Allendorf FW (2010) What can genetics tell us about population connectivity? Mol Ecol 19(15):3038-3051

Melick DR, Kinch JP, Govan H (2012) How global biodiversity targets risk becoming counterproductive: the case of Papua New Guinea. Conserv Soc 10(4):344

Millenium Ecosystem Assessment (2005) Ecosystems and human well-being: synthesis. Island Press, Washington DC

Mitchell VW (1991) The Delphi technique: an exposition and application. Technol Anal Strateg Manag 3:333-358

Moser SC, Ekstrom JA (2011) Taking ownership of climate change: participatory adaptation planning in two local case studies from California. J Environ Stud Sci 1(1):63-74

Murray G, King L (2012) First Nations values in protected area governance: Tla-o-qui-aht Tribal Parks and Pacific Rim National Park Reserve. Hum Ecol 40(3):385-395

Neimanis, V.P. (2007) Crown Land. The Canadian encyclopedia: geography. Historica Foundation of Canada. http://www.thecanadianencyclopedia.ca/en/article/crown-land/. Accessed 12 Feb 2007

Office of the Auditor General of Canada (2013) 2013 Fall report of the Commissioner of the environment and sustainable development. Office of the Auditor General of Canada, Ottawa. http://www.oag-bvg. gc.ca/internet/English/parl_cesd_201311_e_38658.html

Office of the Environmental Commissioner of Ontario (2013) Laying siege to the last line of defence: a review of Ontario's weakened protections for species at risk. Office of the Environmental Commissioner of Ontario, Toronto. http://www.eco.on.ca/uploads/Reports-special/2013\%20Laying\%20Siege\%20to\%20 the $\% 20$ ESA/Laying\%20Siege.pdf

Parks Canada Agency (2008) Principles and guidelines for ecological restoration in Canada's protected natural areas. Parks Canada, Gatineau. http://www.pc.gc.ca/docs/pc/guide/resteco/guide_e.pdf

Schmoldt L, Peterson L (2000) Analytical group decision making in natural resources: methodology and application. Forest Sci 46(1):62-75

Secretariat of the Convention on Biological Diversity (SCBD) (2010a) COP-10 Decision X/2. Secretariat of the Convention on Biological Diversity, Nagoya. https://www.cbd.int/doc/decisions/cop-10/cop-10dec-02-en.pdf

Secretariat of the Convention on Biological Diversity (SCBD) (2010b) Global Biodiversity Outlook 3. Secretariat of the Convention on Biological Diversity, Montréal. https://www.cbd.int/doc/publications/ gbo/gbo3-final-en.pdf

Secretariat of the Convention on Biological Diversity (SCBD) (2014) Global Biodiversity Outlook 4. Secretariat of the Convention on Biological Diversity, Montréal. https:/www.cbd.int/gbo/gbo4/ publication/gbo4-en-hr.pdf

Steffen W, Richardson K, Rockström J, Cornell SE, Fetzer I, Bennett EM, Biggs R et al (2015) Planetary boundaries: guiding human development on a changing planet. Science 347(6223):1259855

Stronghill J, Rutherford MB, Haider W (2015) Conservancies in Coastal British Columbia: a new approach to protected areas in the traditional territories of first Nations. Conserv Soc 13(1):39-50

Tittensor DP, Walpole M, Hill SLL, Boyce DG, Britten GL, Burgess ND, Butchart SHM et al (2014) A midterm analysis of progress toward international biodiversity targets. Science 346(6206):241-244

Turner KL, Bitonti CPH (2011) Conservancies in British Columbia, Canada: bringing together protected areas and first Nations interests. Int Indig Policy J 2(2):3 
Von der Gracht HA (2012) Consensus measurement in Delphi studies: review and implications for future quality assurance. Technol Forecast Soc 79(8):1525-1536

Watson JEM, Dudley N, Segan DB, Hockings M (2014) The performance and potential of protected areas. Nature 515(7525):67-73

Watson JE, Darling ES, Venter O, Maron M, Walston J, Possingham HP, Dudley N, Hockings M, Barnes M, Brooks TM (2015) Bolder science needed now for protected areas. Conserv Biol J Soc Conserv Biol. doi:10.1111/cobi.12645

Woodley S, Bertzky B, Crawhall N, Dudley N, Londoño JM, MacKinnon K, Redford K, Sandwith T (2012) Meeting Aichi Target 11: what does success look like for protected area systems? Parks 18(1):23-36

Worboys G, Francis WL, Lockwood M (2010) Connectivity conservation management: a global guide (with particular reference to mountain connectivity conservation). Earthscan, London

Wyborn CA (2015) Connecting knowledge with action through coproductive capacities: adaptive governance and connectivity conservation. Ecol Soc 20(1):11

Wyborn C, Patrick Bixler R (2013) Collaboration and nested environmental governance: scale dependency, scale framing, and cross-scale interactions in collaborative conservation. J Environ Manag 123:58-67 